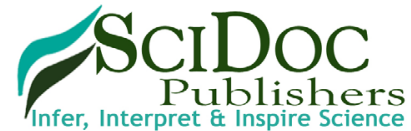

International Journal of Behavioral Research \& Psychology (IJBRP)

ISSN 2332-3000

\title{
Distress and Psychological Impact of Covid-19 Pandemic and Previous Outbreaks Review and Methodological Suggestions
}

Research Article

Giovanni Meledandri ${ }^{1}$, Barbara Trimarco ${ }^{2 *}$

${ }^{1}$ Faculty of Psychology, Department of Human Sciences, Chair of Emerging Diseases, Università degli Studi Guglielmo Marconi, Rome (RM)- 00193, Italy.

${ }^{2}$ Associazione di Psicologia Cognitiva (APC), Viale Castro Pretorio, 116, 00185 Rome, Italy.

Abstract

The current worldwide outbreak of the novel coronavirus Covid-19, originated from Wuhan (China), has spread to 6 continents, 213 countries and territories around the world. This paper aggregates and consolidates the state of the art about Sars Cov2 virology, molecular genetics, immunology, pathogenicity, epidemiology, explores the concept of crisis and psychological effects on population by the ongoing 2020 Covid-19 outbreak crisis vs previous pandemic impacts. The detailed description of this public health threat highlights the great uncertainty surrounding it. Uncertainty and confusion can amplify the psychological impact of this event on the general population. Results are summarized and discussed. Methodological suggestions are provided for studies aimed at investigating psychological effects of critical catastrophic and unexpected life events, such as a pandemic. The analyzed aspects have implications for healthcare professionals in their efforts to promote the psychological well-being of general population during critical unexpected events.

Keywords: CoVid-19, Pandemic, Psychological Impact, Distress

\section{Introduction}

The present worldwide outbreak of the novel coronavirus Covid-19 (coronavirus disease 2019; pathogen: SARS-CoV-2) emerged in Wuhan (China) and has now spread throughout 6 continents, 213 countries and territories around the world, that have reported a total of 9,228,526 confirmed cases, and a death toll of 475,123 deaths (this information includes reports as of 24:00 on June 21st, 2020). COVID-19 epidemic can be considered a global health threat [1]. It has been described as the major outbreak of atypical pneumonia since the severe acute respiratory syndrome (SARS) in 2003. The number of cases and deaths quickly exceeded those of SARS [2,3].

This work provides a detailed description of this public health threat and explores the distress response and psychological impact of recent epidemics (rare, unpredictable and disruptive events) on general population. The detailed description of COVID-19 highlights the great uncertainty surrounding this new disease. Uncertainty and confusion may play an important role in amplifying the psychological impact of this event on general population.
Coronaviruses (CoVs), a large family of single-stranded RNA viruses, can affect animals and humans, producing disease in tissues and organs [4]. CoVs are divided into genera alpha - coronavirus, beta - coronavirus, gamma-coronavirus and delta - coronavirus [5]. CoVs have been identified in several animal hosts [6, 7$]$ all around the world. Six human coronaviruses have been identified: the alpha-CoVs HCoVs-NL63 and HCoVs-229E; the beta-CoVs HCoVs-OC43; the SARS. CoV, causative agent of the severe acute respiratory syndrome SARS [8]; the MERS-CoV, ethiologic agent of Middle East respiratory syndrome MERS [9]. CoVs phylogeny is very old, according to actual and stem natural reservoir animals, and a long host adaption period (25-50 million years) made most of them minor pathogens: they commonly affect hosts mildly or not at all. Also new mammalian CoVs are identified [10]. For example, a HKU2-related coronavirus of bat origin was responsible for a fatal acute diarrhea syndrome in pigs in 2018 [11]. Novel CoVs emerge also in humans, probably due to the worldwide distribution of $\mathrm{CoVs}$ and their ability to adapt viral genome to new hosts [12].

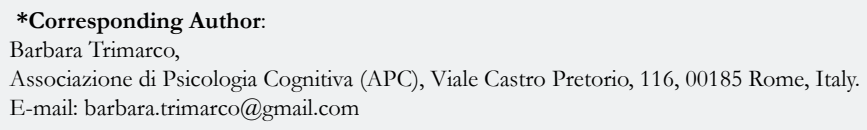

Citation: Giovanni Meledandri, Barbara Trimarco. Distress and Psychological Impact of Covid-19 Pandemic and Previous Outbreaks. Review and Methodological Suggestions. Int Behav Res Psychol. 2021;09(01):275-283. doi: http://dx.doi.org/10.19070/2332-3000-21000049

Copyright: Barbara Trimarco ${ }^{\circ}$ 2021. This is an open-access article distributed under the terms of the Creative Commons Attribution License, which permits unrestricted use, distribution and reproduction in any medium, provided the original author and source are credited. 


\section{COVID-19 etiologic agent: SARS-CoV-2}

A novel Coronavirus is the causative agent of COVID-19. It has been isolated in patients' fluids and cells and its genoma has been fully sequenced [13]. The new virus was named SARS-CoV-2 (Severe Acute Respiratory Syndrome - Coronavirus - 2) and classified in the subgenus Sarbecovirus.

It has been hypothesized that SARS-CoV-2 may have been spread to humans through intermediate hosts, such as bats [14], though the actual route of transmission is still debatable.

Coronaviridae family viruses have a single-strand, positive-sense RNA genome ranging from 26 to 32 kilobases in length [15].

The new virus is more similar to two bat-derived coronavirus strains, bat-SL-CoVZC45 and bat-SL-CoVZXC21, than to any other known human-infecting coronaviruses, including the virus that caused the SARS outbreak of 2003. Nevertheless, although, SARS-CoV-2 is closer to bat-SL-CoVZC45 and bat-SL-CoVZXC21 at the whole-genome level, its receptor - binding domain falls within lineage $\mathrm{B}$ and is closer to that of SARS-CoV, enabling it to recognize and link the human ACE-2s receptors and fuse straightforward with cell membrane. The receptor-binding domain of SARS-CoV-2 is its most relevant spill over mutation [13]. The SARS-CoV-2 human pathogenicity relies mainly upon this mutated receptor-binding domain.

As above mentioned, the phylogenetic analysis showed that batderived coronaviruses fell all within subgenera of the genus betacoronavirus. Additionally, bat-derived coronaviruses fell in basal positions in the subgenus Sarbecovirus [16]. The previous data are consistent with a bat reservoir for coronaviruses, according to common RNA viruses and bats CCS (Critical Community Size) [17], and in particular for SARS-CoV-2. However, the role of bats as reservoir by itself cannot provide full satisfactory evidence for the acquisition of the mutated receptor-binding domain. Another peculiarity of SARS-CoV-2 genome is the presence of a RNAdependent RNA polymerase out from ancient negative-strand RNA virus bat gene [18]. Otherwise inexplicable, this suggested that at least another source acted as an intermediate host between bats and humans.

\section{Mutagenecity of SARS-CoV-2}

As a typical RNA virus, SARS-CoV-2 shows its particular spontaneous mutagenicity. The average evolutionary rate for coronaviruses is roughly $10^{-4}$ nucleotide substitutions per site per year, with mutations arising during every replication cycle [15]. It is remarkable that the sequences of SARS-CoV-2 from different patients described during the emerging outbreak in Wuhan were almost identical, with a sequence identity greater than $99.9 \%[13]$.

This finding suggests that SARS-CoV-2 originated from one only source, within a very short period, and was quickly detected.

\section{The reservoir and spillover of SARS-CoV-2}

Mass media delivered the news that SARS-CoV-2 started in a wildlife market in Wuhan. Nevertheless, the source of the virus (an animal carrying this pathogen in its body) has not been identi- fied so far, either in the market or somewhere else.

Two groups of coronaviruses related to the virus behind the human pandemic have been identified in Malayan pangolins smuggled into China [19], but none of these suspect species has been definitely shown to be involved in this outbreak [20].

Bats also host coronaviruses [17], which are even closer to the human virus, except in one genoma key area - the part that enables the virus to invade cells $[10,13]$.

The outbreak of SARS-CoV-2 was reported for the first time in late December 2019. During this season most bat species are hibernating in Wuhan. No bats were found at the Huanan market [13]. The sequence identity between 2019-nCoV and its close relative bat-SL-CoVZC45 and bat-SL-CoVZXC21 was less than $90 \%$, which is reflected in the relatively long branch between them. Hence, bat-SL-CoVZC45 and bat-SL-CoVZXC21 are not direct ancestors of SARS-CoV-2 [13].

In Xiao et al.'s study [19], one coronavirus isolated from a Malayan pangolin showed high levels of amino acid identity with SARSCoV-2 in the E, M, N and S genes (respectively, 100\%, 98.6\%, $97.8 \%$ and $90.7 \%$ ). The receptor-binding domain within the $\mathrm{S}$ protein of the Pangolin-CoV is very similar to that of SARS$\mathrm{CoV}-2$, with one noncritical amino acid difference. According to the authors, results of comparative genomic analysis suggested that Covid-19 may have emerged from the recombination of a Pangolin-CoV-like virus with a Bat-CoV-RaTG13-like virus [19].

Nevertheless, to stay with the SARS-CoV example, it has been described that few alterations in the SARS-CoV spike protein, compared to related bat $\mathrm{CoV}$, enabled binding to its host receptor ACE-2 and thus became capable of infecting humans [21]. All SARS-like-CoV viruses so far detected in bats lack these alterations and are, therefore, not predictable in their capacity of infecting humans [21]. At the nucleic acid level, the different function of proteins is key for the host range, even though strains might appear similar: the similarity is not enough to analyze viruses' potential to spill over and infect humans or to predict their virulence [18].

Regarding the hypothesis of a pangolin acting as the intermediate host needed to let the SARS-CoV-2 spill over to infect humans, the acquisition of its mutated receptor-binding domain cannot be explained by similarity, it has not been demonstrated, nor found in pangolin genetics [22]. Stem pangolins and bats shared the same habitat for ages, for over 30 million years [23]. In such a long time, a cross-host evolution of coronavirus, suggesting a rapid evolving process of viral proteins, in bat [10] and pangolin as well, has not been detected. Major genetic variations in some critical genes, particularly the spike genes, essential for the transition from animal-to-human transmission to human-to-human transmission, much like their adaptation in the human host [24], have not been reported yet.

\section{Epidemiology and pathogenicity of SARS-CoV-2}

According to the WHO [3], SARS-CoV-2 human-to-human transmission has been observed via virus-laden respiratory droplets. The average incubation period is estimated to be 5.2 days (3-20 days), with significant variation among patients and spread from 
asymptomatic patients is admitted [25]. The most frequent symptoms of infection include fever, chills, cough, diarrhea; coryza, breathing difficulty, fatigue, myalgia, nausea, vomiting are also reported. Other unusual symptoms include neurological syndromes (e.g.confusion, stroke and seizures) diminished sense of smell (anosmia) and taste (ageusia), heart and coagulation ailments [26]. Coronavirus hits females more than men: gender ratio 1.2-1.6 [27]. Older men with medical comorbidities are more likely to get infected, with worse outcomes. Severe cases can lead to cardiac injury, respiratory failure, acute respiratory distress syndrome, disseminated intravascular coagulation and death. The provisional case fatality rate by $\mathrm{WHO}$ is around $2 \%$, but some researchers estimate the rate to range from $0.3 \%$ to $0.6 \%$ [3].

\section{Aspects of immunity of SARS-CoV-2}

SARS-CoV-2 is an obligate intracellular parasite: it does not live outside the cell but can keep its infecting ability in environment [3]. In the host extracellular viruses may be removed by humoral and cellular mechanisms, but the intracellular replicative steps of coronaviruses and virus-infected cells-that (or if) they have developed virus specified antigens on their surface-are the major targets for the host immune response. The infectious virions spread [28] via extracellular spread (released from the infected cell in the extracellular fluids and then eventually outside the host); intercellular spread (spread from cell to cell through cell fusion, without contact with the extracellular environment) [29]; vertical spread: the viral genome becomes integrated into the host genome and is passed from parent cell to progeny during meiosis. In this latter case many or all virus antigens are absent on the cell surface, so that the virus is undetectable by the host. The retroviruses genes usually adopt this mechanism.

In the host SARS-CoV-2 spread occurs both at a local level (mucosal surface or organ) or via the bloodstream, with subsequent dissemination through all organs.

SARS-CoV-2 spread mechanisms may limit exposure of extracellular virus to humoral or cellular host defense mechanisms. Moreover, virus serologic variants evolve, with minimal crossreactivity among them. Camouflage and latency mechanisms in SARS-CoV-2 require further investigation [30]. These mechanisms could also enable a long or indefinite persistence of the SARS-CoV-2 in the host, with minimal or no clinical evidence, similarly to what happens for other viruses.

\section{The COVID-19 pandemic and the lockdown}

On March 11th, 2020, the WHO, declared COVID-19 a pandemic, considering that more than 118,000 cases had been detected in over 110 countries and territories and the risk of further global spread.

The WHO defines a pandemic [3] as the "worldwide spread of a new disease", though the specific threshold for meeting that criteria is not always obvious. The term was most often applied to new influenza strains, and the CDC affirms it is used when viruses "are able to infect people easily and spread from person to person in an efficient and sustained way" in multiple regions. The declaration refers to the spread of a disease, rather than the severity of the illness it causes.
In order to retard the spread of the virus, a lockdown was imposed in several countries: school were closed and the lockdown was extended to all non-essential activities. Many citizens have remained at home for various weeks, socially isolated, with important economical and psychological consequences. Previous research has revealed a wide range of psychosocial impact on people during outbreaks of infection. Individuals are likely to experience fear of becoming ill or dying, helplessness, and stigma [31].

Negative emotions are likely to appear with the shutdown of schools and business activities [32]. For instance, during the SARS disruption, several studies researched the psychological impact on the healthy community and significant psychiatric symptoms were found [33].

\section{Additional considerations in the definition and concept of crisis}

A crisis may be defined as a very " "rapid change (...) that provides an individual with a 'no exit' challenge (...) to alter her or his conduct in some manner" " [34]. A crisis is a physiological emergency and acts on the individual as the deprivation of oxygen. The concept of crisis is very influential in community mental health and preventive modalities of care. The term crisis comes from the Greek word" $\chi \varrho i v \omega "$, which means "to decide". The term is used to describe a point in the course of a disease, or an event during the life course, which is decisive for either recovery or death. The term means a critical turning point in the progress of some state or condition in which a decisive change, for better or worse, is essential and about to happen. The idea of a change can lead the individual to think and act differently, according to her/his relationship to the problem and implies an ability to cope with the distress. Additionally, a crisis is precipitated by a situation that disturbs prior adaptation. Theorists $[35,36,37]$ postulate some essential features of a crisis. First it is a stressful or dangerous event requiring change: a hazardous life event. Hazardous or stressful life events can be classified as expected or unexpected. Unexpected events are those whose timing cannot be predicted. The possibility to consider any preventive action or position facing a crisis relies upon its features. A second characteristic of a crisis depends on the way the new problem affects the individual on her/his life: material and physical integrity (health), psychological resources, her/his family, social context or any other person who might play a role in the individual social support network.

\section{The impact of life events and stressors on psychological health}

Investigations focusing on personal life events of otherwise ordinary people, undergoing some kind of situational crisis, evidenced a higher than expected incidence of disorders [38, 39]. Holmes and Rahe [40] and Rade et al. [41] recognized that different events required different change and adaptation, affecting more or less each individual. In the following studies the term life event emerged and has been commonly used.

During an unexpected worldwide crisis, such as a pandemic, which leads several countries in the world to adopt extreme measures to contain the contagion, the exploration of distress response and psychological impact of this event on general population plays an important role in preventing psychological health emergencies, originating during or soon after the public health crisis. To this aim, our review focuses not only on the few data on psychological 
impact of the current pandemic, but also on the results of studies exploring distress and psychological symptoms in people of affected countries during previous outbreaks. These data may have important implications for healthcare professionals.

\section{Materials and Methods}

In order to be analyzed, the results from descriptive studies must be leaded to common - quantitative (numeric) or qualitative (e.g.categorical, continuous) - shape, able to identify variables and casual roles. Data analysis for any given outcome includes two possibility: univariate and multivariate analyses. Univariate analyses are used to identify individual predictors of the investigated outcome and to establish relationships among the dependent and independent variables. The relationship between categorical outcomes can be appropriately measured using the chi-square test or Fisher's exact test. In case of continuous outcomes (e.g. illness days) the relationship to continuous independent variables (e.g. age) can be assessed by examination of X-Y scatter plots; if that relationship is linear - or amenable to a linear one - it can be quantified using Pearson's correlation. If it is a not linear relationship, the computation must be estimated $[42,43]$.

It is also very important to plot the data in order to explore any relationships that might exist. According to many published data, in CoVid 19, the plots of death rate and morbidity show monotonic (not linear or not only linear) relationships with associated independent variables as age or time. In a monotonic relationship, the variables tend to move in the same relative direction, but not necessarily at a constant rate. In a linear relationship, the variables move in the same direction at a constant rate. The plot can help to get rid of how the variables move: linear relationships are frequently also monotonic.

We performed a systematic search for the available literature using PubMed, SCOPUS and Web of Science. The following key words were searched: psychological adjustment, psychiatric symptoms, coping, stress, outbreak, epidemic. Papers over the last 15 years (2005-2020) were considered for inclusion. Only studies in English and papers from peer-reviewed journals were included. Studies that included only health workers as participants were excluded. Studies that explored psychological adjustment, coping or stress responses without relating the concepts to epidemics were also excluded.

\section{Results}

We identified 22 studies from the database search, of which 9 were included in the review. Of the 9 included articles 3 were qualitative studies and 6 were quantitative studies. Overall, 4 studies focused on the SARS epidemic, 2 studies examined the Ebola epidemic, two studies covered the H1N1 pandemic and 1 study focused on the COVID-19 pandemic. The results of the different studies are presented below, according to the specific epidemic. The results are also summarized in Tables 1 and 2 .

\section{SARS epidemic}

Cheng \& Cheung [44] designed a prospective, multiple time-point study, assessing trait anxiety and coping flexibility in seventy-two Hong Kong undergraduates, who had been assessed in an earlier study, five months earlier. They reported their anxiety and coping at four time points during the outbreak, during the four-week study period. Fluctuations in state anxiety were detected across time points. Results from hierarchical linear modeling revealed that trait anxiety and the situation-appropriate coping strategies of avoidance and personal hygiene practice accounted for changes in state anxiety. Trait anxiety assessed 5 months earlier could predict initial levels of state anxiety, but the positive association between trait and state anxiety was only present at the initial time points: individual differences in state anxiety became minimal at the following time points. Situation - specific coping strategies of personal hygiene practice and avoidance could also predict fluctuations in state anxiety: results showed that personal hygiene practice and avoidance played a stronger role in explaining state anxiety. The authors found that individuals who used more avoidance experienced less state anxiety during the four-week period. The authors hypothesized that the use of avoidant strategies, which can be defined as efforts to escape from the stressful event [45], may have had a role in easing anxiety during the outbreak, as SARS outbreak was a stressful event perceived as uncontrollable. $\mathrm{Yu}$ and coworkers [46] focused on depressive symptoms and emotional distress before and during SARS outbreak in a sample of Hong Kong midlife women $(n=126)$. As expected, they found higher levels of depressive symptoms and emotional distress during the epidemic. Using logistic regression analysis, the authors identified three factors significantly associated with emotional distress during SARS: feeling scared, restless sleep and financial loss. The latter was the only factor independently related to the increase in stress level. Additionally, personal perception of risk of infection was correlated with psychological distress.

Peng and colleagues [47] explored the post-crisis psychological distress four months after the resolution of the SARS outbreak in Taiwan $(n=1278)$. In particular, the authors explored variables comprised perceptions and attitudes towards SARS, behavior and SARS-related experiences and psychological distress. About 9\% of the participants reported that their perceptions of life became more pessimistic following the SARS crisis and the prevalence of psychiatric morbidity was around $11 \%$. The authors found a number of major predictors of higher levels of pessimism after the SARS outbreak: demographic factors, perception of SARS and preparedness, knowing people or having personal experiences of SARS-related discrimination, individual worries and psychiatric morbidity.

Main and colleagues [48] analyzed SARS related stressors (participants' experience of SARS-related stressful events, such as having had a family member suspected of having SARS) coping strategies, psychological symptoms, perceived general health and life satisfaction in a sample of 381 undergraduate students recruited from universities of Beijing (China). As hypothesized by the authors, experience of SARS-related stressors was positively associated with psychological symptoms. Participants' use of avoidant and seeking social support coping positively predicted psychological symptoms, while active coping positively predicted life satisfaction. Additionally, significant interactions between coping and stressors, able to predict perceived general health, were detected for the three coping strategies (active, avoidant, and social support seeking coping).

The authors found a stress buffering effect of coping: notwithstanding the type of coping, the number of SARS-related stress- 
Table 1. Details of the studies included in the review (year of the epidemic, epidemic, country, investigated variables, instruments, sample size and gender distribution).

\begin{tabular}{|c|c|c|c|c|c|c|c|}
\hline Paper & $\begin{array}{l}\text { Year of the } \\
\text { epidemic }\end{array}$ & Epidemic & Country & Variables & Instruments & $\mathbf{N}$ & Males \\
\hline $\begin{array}{l}\text { Cheng \&Cheung, } \\
2004\end{array}$ & 2003 & SARS & Hong Kong & $\begin{array}{l}\text { Anxiety; coping responders; Situation- } \\
\text { specific coping strategies. }\end{array}$ & $\begin{array}{l}\text { State-Trait Anxiety Inven- } \\
\text { tory; Coping } \\
\text { Flexibility Inventory; } \\
\text { ad-hoc questionnaire as- } \\
\text { sessing strategies for cop- } \\
\text { ing with SARS. }\end{array}$ & 72 & 31 \\
\hline Yu et al., 2005 & 2003 & SARS & 12 & $\begin{array}{l}\text { Depressive symptoms and emotional dis- } \\
\text { tress before and during SARS. }\end{array}$ & $\begin{array}{l}\text { Center of the Epidemio- } \\
\text { logical Study of Depres- } \\
\text { sion Scale (CES-D) and } \\
\text { Perceived Stress Scale } \\
\text { (PSS). }\end{array}$ & 126 & 0 \\
\hline Rabelo et al., 2016 & 2014-15 & Ebola & Liberia & $\begin{array}{c}\text { Mental health distress during treatment at } \\
\text { Ebola Treatment Unit; } \\
\text { Coping strategies to overcome } \\
\text { mental health distress in Ebola Treatment } \\
\text { Unit; mental health distress after } \\
\text { discharge from Ebola Treatment Unit; } \\
\text { coping strategies after discharge } \\
\text { from Ebola Treatment Unit. }\end{array}$ & Focus group. & 17 & 8 \\
\hline Schwerdtle, 2017 & 2014-15 & Ebola & $\begin{array}{l}\text { Liberia, Sierra } \\
\text { Leone. }\end{array}$ & $\begin{array}{l}\text { experiences of Ebola survivors (causes of } \\
\text { distress, sources of resilience). }\end{array}$ & Semi-structured interview. & 25 & 0 \\
\hline McCauley et al., 2013 & 2009 & H1N1 & $\begin{array}{l}\text { United States, } \\
\text { New England. }\end{array}$ & $\begin{array}{l}\text { psychological processes of cue convergence } \\
\text { and associative priming; stress and coping. }\end{array}$ & Focus group. & 46 & 17 \\
\hline Taha et al., 2014 & 2009 & H1N1 & Canada & $\begin{array}{l}\text { H1N1 experience; intolerance of uncertain- } \\
\text { ty; Appraisal of ambiguous situations; stress } \\
\text { appraisal measure; Self-evaluation question- } \\
\text { naire / state anxiety. }\end{array}$ & $\begin{array}{l}\text { Ad-hoc questionnaires; } \\
\text { The stress appraisal meas- } \\
\text { ure; State-Trait Anxiety } \\
\text { Inventory. }\end{array}$ & 316 & 59 \\
\hline Main et al., 2011 & 2003 & SARS & China & $\begin{array}{l}\text { SARS related stressors, coping strategies, } \\
\text { psychological symptoms, perceived general } \\
\text { health, life satisfaction. }\end{array}$ & $\begin{array}{c}\text { Ad hoc checklist measure } \\
\text { to assess participants' ex- } \\
\text { perience of SARS-related } \\
\text { stressors; } \\
\text { Nine subscales from the } \\
\text { Coping Inventory; } \\
\text { 90-item Symptom Check- } \\
\text { list (SCL-90); } \\
\text { Ad hoc single-item self- } \\
\text { rating of perceived healt; } \\
\text { The 5-item Life Satisfac- } \\
\text { tion Scale. }\end{array}$ & 381 & 162 \\
\hline Peng et al., 2010 & 2003 & SARS & Taiwan & $\begin{array}{l}\text { Perceptions and attitudes towards SARS; } \\
\text { Behavior and SARS-related experiences; } \\
\text { Psychological distress } 4 \text { months after SARS } \\
\text { epidemic resolution. }\end{array}$ & $\begin{array}{c}\text { Ad hoc questionnaires; a } \\
\text { single } \\
\text { question related to partici- } \\
\text { pant's change in perception } \\
\text { of life plus the five-item } \\
\text { Brief Symptom } \\
\text { Rating Scale (BSRS-5). } \\
\end{array}$ & 1278 & 643 \\
\hline Wang et al., 2020 & $2019-20$ & COVID-19 & China & $\begin{array}{c}\text { physical symptoms; contact history with } \\
\text { COVID-19; knowledge and concerns about } \\
\text { COVID-19; precautionary measures against } \\
\text { COVID-19; additional information required } \\
\text { with respect to COVID-19; the psycho- } \\
\text { logical impact of the COVID-19 outbreak; } \\
\text { mental health status. }\end{array}$ & $\begin{array}{l}\text { Ad-hoc questionnaires; } \\
\text { Impact of Event Scale-Re- } \\
\text { vised (IES-R); Depression, } \\
\text { Anxiety and Stress Scale } \\
\text { (DASS-21). }\end{array}$ & 1210 & 396 \\
\hline
\end{tabular}

ors was positively associated with perceived general health only at low levels of coping. The authors commented on this result hypothesizing that when stressors are large-scale and perceived as severe and out of control, any type of coping could be helpful in reducing distress.

\section{H1N1 outbreak}

McCauley and colleagues [49] performed an exploratory qualitative study on the psychological processes of the associative priming, through which many people likely merged the news of the
H1N1 epidemic with prior cognitive scripts that blamed Latino immigrants for various social problems. The authors used a transactional model of stress andcoping to analyze the transcripts from focus groups, in order to examine the ways in which a group of American residents evaluated the H1N1 threat, processed information about stereotypes and stigmas and developed individual strategies to cope with these stressors. Participants in all focus groups reported similar processes of stress and coping in reaction to H1N1 threat; individual responses varied by ethnicity. This study highlighted some of the ways in which epidemics can be relevant sources of individual and social stress. Ilness-related stress 
Table 2. Statistical methods and quantitative results.

\begin{tabular}{|c|c|c|}
\hline Paper & Statistical method & Quantitative results (when where as available) \\
\hline Cheng \& Cheung, 2004 - SARS & Hierarchical linear modeling & $\begin{array}{l}20 \% \text { of the variance in state anxiety over time was attributable to interindi- } \\
\text { vidual differences, } 80 \% \text { of the variance was attributable to intra-individual } \\
\text { differences across time points. This result indicates that the state anxiety } \\
\text { reported by participants varied across the } 4 \text {-weeks period. } \\
\text { The test statistic for the linear model against the baseline model was w } 2(3) \\
524.07, \mathrm{p}<.001 \text {, whereas the test statistic for the quadratic model against } \\
\text { the linear model was w2(4) } 540.78 \text {, p }<.001 \text {. }\end{array}$ \\
\hline Yu et al., 2005 - SARS & $\begin{array}{l}\text { Univariate analysis: ANOVA p } \\
\text { Value; binary logistic regression }\end{array}$ & $\begin{array}{c}\text { Factor associated with the mild depression and emotional distress OR } \\
\text { positively related to "Felt scared" and "Financial losses", } \mathrm{p}<.05 \text {. }\end{array}$ \\
\hline $\begin{array}{l}\text { Rabelo et al., } 2016 \text { - EBOLA } \\
\text { survivors }\end{array}$ & Qualitative study & -------- \\
\hline Schwerdtle 2017 - EBOLA survivors & Qualitative study & ------- \\
\hline McCauley et al 2013 - H1N1 & Qualitative study & ------- \\
\hline Taha et al 2014 - H1N1 & $\begin{array}{c}\text { Descriptive statistics; Pearson cor- } \\
\text { relations; Hierarchical regression } \\
\text { analysis }\end{array}$ & $\begin{array}{l}\text { Stressfulness increases according to appraisals of ambiguous life events and } \\
\text { less to appraisals of viral threat. Pearson correlations among stressfulness } \\
\text { of life events, anxiety and intolerance to uncertainty are evidenced, } \mathrm{p}<.01 \text {. }\end{array}$ \\
\hline Main et al.,, 2011 - SARS & $\begin{array}{l}\text { Zero order correlations; } \\
\text { Descriptive statistics; } \\
\text { Multiple Regression analyses }\end{array}$ & $\begin{array}{l}\text { The relations of stressors and coping suggested that the number of stress- } \\
\text { ors and use of avoidant coping strategies positively predicted psychological } \\
\text { symptoms, } \mathrm{p}<.01 \text {. Support seeking behaviors positively predicted psycho- } \\
\text { logical symptoms, } \mathrm{p}<.001 \text {. }\end{array}$ \\
\hline Peng et al 2010 - SARS & $\begin{array}{l}\text { Descriptive statistics; } \\
\text { Multivariate logistic regression }\end{array}$ & $\begin{array}{c}\text { Age equal or }>50 \text {, perceived survival rate have been quaranteened and } \\
\text { education level positively correlated to higher score in OR for psychiatric } \\
\text { morbidity (prevalence } 11.7 \% \text { ). }\end{array}$ \\
\hline Wang et al 2020 - COVID-19 & $\begin{array}{l}\text { Descriptive statistic; } \\
\text { Percentages of response; } \\
\text { Linear regression }\end{array}$ & $\begin{array}{l}\text { Associations between demographic variables and psychological impact of } \\
\text { COVID-19 were investigated. Associations were found present between all } \\
\text { independent and dependent variables, } \mathrm{p}<.05-.01 \text {. }\end{array}$ \\
\hline
\end{tabular}

was shown to lead to the stigmatization of marginalized social groups, as well as to anxiety about personal and family health and to troubles in working and social relationships.

A different study on H1N1 outbreak was developed in Canada. In the spring following the H1N1 peak, when the pandemic was visibly diminishing, but vaccination was still available, Taha and coworkers [50] analyzed H1N1 experience, uncertainty intolerance, ambiguous situation appraisal, stress appraisal and anxiety in a sample of 316 adults. The participants were presented with several scenarios regarding viral threats. They reported moderate anxiety, regardless of the specific viral threat (familiar vs. unfamiliar), considered the threats moderately stressful and believed that they would have control in this situation. Nevertheless, high levels of anxiety accompanied the viral threat in individuals with high intolerance of uncertainty, with the mediation of appraisal aspects (i.e. control and stressfulness). Additionally, participants used to appraise ambiguous life events as stressful, the viral threat appraisals were accompanied by even higher levels of anxiety.

\section{Ebola outbreak}

The studies on Ebola emerged from our bibliographic research were both focused on Ebola survivors. Rabeloet al. [51] analyzed mental health distress during treatment at a Liberian Ebola Treatment Unit (ETU), coping strategies to overcome mental health distress in ETU and mental health distress after discharge from ETU in a qualitative study. Using focus group technique, the authors found that post traumatic stress reactions and symptoms of depression were common among the Ebola survivors exposed to death in the ETU and stigma in the communities. The main stressors during the hospitalization were the daily exposure to corpses, the patient's isolation from family and worries about his/ her well-being; sometimes, also the perception of disrespect by
ETU staff could generate relevant distress. The support of family, friends, and prayer, when available, allowed the survivors to cope with their psychological distress. Psychosocial counseling and the survivor's network helped those excluded from society, because of the stigma and fear of contagion, give a meaning to life after Ebola.

Causes of distress and sources of resilience were the focal points of Schwerdtle and colleagues' study [52]. Using focus group, they involved 25 participants in Liberia and Sierra Leone and identified two main themes: "causes of distress" and "sources of resilience." Each main theme comprised two further sub-themes, respectively: the "multiplicity of death," "abandonment," "self and community protection and care" and "coping resources and activities."

\section{Covid-19 pandemic}

A recent study investigating psychosocial impact of SARS-CoV-2 in Chinese population found that, during the initial phase of the COVID-19 outbreak, $53.8 \%$ of the respondents $(n=1210)$ rated the psychological impact of the outbreak as moderate-to-severe, $28.8 \%$ reported moderate - to - severe anxiety, $16.5 \%$ reported moderate to severe depressive symptoms and $8.1 \%$ reported moderate to severe stress levels [53]. Most respondents were worried about their family members contracting the virus $(75.2 \%)$. Female gender, student status, specific physical symptoms and poor self-rated health status were significantly associated with a greater psychological impact ofthe outbreak and higher levels of stress, anxiety, and depression. Specific up-to-date and accurate health information and particular precautionary measures were associated with a lower psychological impact of the outbreak and lower levels of stress, anxiety, and depression. 


\section{Discussion}

The descriptive or observational studies that investigate distress and psychological symptoms in general population during epidemics have focused on very different variables and used varied study designs, leading to mixed results.

The uncertainty produced by an unexpected, uncommon and threatening event, such as an epidemic, may play an important role in modulating the distress and psychological response of general population.

Higher levels of depressive symptoms and emotional distress [46] and fluctuations in state anxiety [44] have been highlighted during the outbreaks.

Moderate to severe psychological impact related to the outbreak and anxiety seems common [53], whereas less participants reported moderate to severe depressive symptoms stress levels.

It is not easy to analyze these variables in a sudden outbreak condition, because of the lack of previous time points analyses, before the beginning of the epidemics. This may suggest the importance of continuous monitoring of psychological parameters in samples from general population, in order to have a baseline in case of unexpected events which may put general psychological health at risk.

Many of the studies considered in this work analyze the factors which may have a role in mediating the effect of stressors on individual psychological well-being.

Feeling scared, restless sleep and financial loss were associated with emotional high stress during SARS [46], experience of SARS-related stressors was positively associated with psychological symptoms and use of avoidant and seeking social support coping positively predicted psychological symptoms [48]. Nevertheless, coping had a stress buffering effect: notwithstanding the type of coping, the number of SARS-related stressors was positively associated with perceived general health only at low levels of coping [48].

Uncertainty tolerance has also an important role: individuals with high intolerance of uncertainty have been shown to be more likely to appraise a virus as being more stressful and less controllable and to experiment high anxiety, whereas an optimism bias seems to protect most individuals from feeling anxious about new hypothesized viral threats [50].

Epidemics can increase not only individual, but also social stress: as McCauley and colleagues [49] showed in their study on H1N1 epidemics, illness-related stress can lead to the stigmatization of marginalized social groups, to anxiety about personal and family health and to troubles in working and social relationships.

The condition of survivors who have experienced the illness appears quite different from that of general population, as the studies about ebola epidemics showed: the support of family, friends, prayer, psychosocial counseling had an important role for the survivors to cope with their psychological distress [51]. Multiplicity of death and abandonment were the main causes of distress, whereas self and community protection and care and coping resources and activities were the key aspects for resilience according to Schwerdtle and colleagues' study [52].

The need to find and to measure the relationship between multiple variables, a feature common to the aim of all the studies analyzed in this review, is the basis of the type of analysis most frequently used by researchers.

The analysis of variance or multiple regression procedure is in fact the most commonly used quantitative approach to observe the behavior of a dependent variable $\mathrm{X}$ which is identified on the basis of the nature of the phenomenon being studied. It is worth to summarize some considerations about this type of statistical analysis methodology.

The relationship that link a dependent variable $\mathrm{X}_{1}$ to the other variables $\mathrm{X}_{2}, \mathrm{X}_{3}, \ldots, \mathrm{X}_{\mathrm{n}}$ (independent variables or regressors) expresses the way in which $\mathrm{X}_{1}$ varies with the change of the other variables. The factors that can affect $\mathrm{X}_{1}$ are many and not all quantifiable. For this reason, it is essential to select, for the analysis purposes, only the regressors that are truly relevant for the research purposes. There will therefore be factors (known and unknown variables) excluded from the selection, and all of these are collected in one common variable, indicated with the Greek letter $\varepsilon$, as in equation 1 .

All the studies analyzed show - in some way - the role that different circumstances - stressors or life events - played in determining the stress / crisis effect. The stressors are the independent variables $\left(\mathrm{X}_{\mathrm{n}}\right)$ and the crisis the dependent variable $\mathrm{X}_{1}$. The relationship that links to each other is represented by function 1, which describes the law of dependence, and is noted in the form(1):

$\mathrm{X}_{1}=\mathrm{f}\left(\mathrm{X}_{2}, \mathrm{X}_{3}, \ldots, \mathrm{Xn}, \varepsilon\right)$

The trend of the function of $\mathrm{X}_{1}$ in equation 1 is crucial to understand the relationship between the variables that represent the facts. The regression coefficient would be unique if $\mathrm{X}_{1}$ depended only on one variable $\left(\mathrm{X}_{2}\right)$, it would be indicated by the Greek letter $\beta$, and the equation would be written as follows (2):

$\mathrm{X} 1=\beta_{1}+\beta_{2} \mathrm{X}_{2}+\ldots \beta_{\mathrm{n}} \mathrm{X}_{\mathrm{n}}+\varepsilon$

However, the number of experimental observations (both known and unknown) can often be greater than the number of parameters and an estimate able to cumulate many regression coefficients must be obtained according to the experimental data, these based on the samples. It is indicated with the Latin letter b, and the equation is transformed as follows (3):

$\mathrm{X}_{1}=\mathrm{b}_{1}+\mathrm{b}_{2} \mathrm{X}_{2}+\ldots \mathrm{b}_{\mathrm{n}} \mathrm{X}_{\mathrm{n}}+\varepsilon$

The choice of variables must be accurate enough to verify the need to include in the equation only the variables that, when their value changes, provide a factual contribution to the variation of the dependent variable $\mathrm{X}_{1}$. An increase in the number of variables enclosed in the regressive analysis does not consequently increase the efficiency of the analysis itself.

The selection of which variables to insert has, therefore, the crucial role in the analysis results. There are procedures to conduct 
this choice in the most correct way, starting either from the significance of each single regression coefficient, discarding the less significant ones (backwards procedure), or by selecting as the first independent variable the one that has the highest simple correlation coefficient with the dependent variable $\mathrm{X}_{1}$, until finding the highest correlation coefficient between variables (onward procedure) until there are no more variables to insert or remove. For a complete discussion of these techniques, see their detailed statistical description [54].

There is no perfect method for choosing variables, more than ever during the exploratory phase of a study, and practical decisions need to be made. Sometimes some variables do not show significant partial regression coefficients, but have a relevant logical significance, and so must be maintained. In other case variables must be removed which have a high significance of their partial regression coefficient but would not have any logical sense.

The discussion conducted so far has to be applied during the design phase of any research that intends to provide a concrete contribution to the eventuality and strength of a relationship between active factors in producing psychological effects and measures of the investigated effect itself.

Highlighting and measuring the possible relationship between stressors or life events and crisis conditions or psychopathological effects, requires the careful selection and clear measurement of the characteristics and dimensions of the variables under investigation for - and only for - the purpose of the condition towards which the effect of this relationship is supposed to operate.

This review suggests that future research on the correlation between stressful events and psychopathological consequences like any correlation research that uses regressive analysis - should always be preceded, since its planning and design phase, by the selection and quantitative validation of independent variables to select, in order to avoid uncertainty or biased conclusions.

The analyzed aspects also have important implications for healthcare professionals: a particular attention should be paid to the promotion of psychological well-being of general population during critical and unexpected events. Available public psychological healthcare may help prevent the development of more serious psychopathological symptoms after the outbreaks are over.

For future research, it may be important to carry out follow-up studies to measure the effects over time, since it is reasonable that after a period of time has passed from the start of the outbreak different re-adaptation responses may appear.

\section{Funding}

This research did not receive any specific grant from funding agencies in the public, commercial, or not-for-profit sectors.

\section{References}

[1]. Mahase E. China coronavirus: WHO declares international emergency as death toll exceeds 200. BMJ. 2020 Jan 31;368:m408. Pubmed PMID: 32005727.

[2]. Hawryluck L, Gold WL, Robinson S, Pogorski S, Galea S, Styra R. SARS control and psychological effects of quarantine, Toronto, Canada. Emerging infectious diseases. $2004 \mathrm{Jul} ; 10(7): 1206-1212$.

[3]. WHO. Coronavirus. Retrieved 25 June 2020 from.

[4]. Weiss SR, Leibowitz JL. Coronavirus pathogenesis. InAdvances in virus research 2011 Jan 1;81:85-164.

[5]. Yang D, Leibowitz JL. The structure and functions of coronavirus genomic 3' and 5' ends. Virus Res. 2015 Aug 3;206:120-33. Pubmed PMID: 25736566.

[6]. Cavanagh D. Coronavirus avian infectious bronchitis virus. Vet. Res. 2007 Mar 1;38(2):281-97.

[7]. Ismail MM, Tang Y, Saif YM. Pathogenicity of turkey coronavirus in turkeys and chickens. Avian Dis. 2003 Jul;47(3):515-22.

[8]. Drosten C, Günther S, Preiser W, Van Der Werf S, Brodt HR, Becker S, et al. Identification of a novel coronavirus in patients with severe acute respiratory syndrome. N Engl J Med. 2003 May 15;348(20):1967-76.

[9]. Zaki AM, Van Boheemen S, Bestebroer TM, Osterhaus AD, Fouchier RA. Isolation of a novel coronavirus from a man with pneumonia in Saudi Arabia. N Engl J Med. 2012 Nov 8;367(19):1814-20.

[10]. Calisher CH, Childs JE, Field HE, Holmes KV, Schountz T. Bats: important reservoir hosts of emerging viruses. Clin Microbiol Rev. 2006 Jul 1;19(3): 531-45.

[11]. Zhou P, Fan H, Lan T, Yang XL, Shi WF, Zhang W et al. Fatal swine acute diarrhoea syndrome caused by an HKU2-related coronavirus of bat origin. Nature. 2018 Apr;556(7700):255-258. doi: 10.1038/s41586-018-0010-9. Epub 2018 Apr 4. Pubmed PMID: 29618817.

[12]. Cui J, Li F, Shi ZL. Origin and evolution of pathogenic coronaviruses. Nat. Rev. Microbiol 2019 Mar;17(3):181-92.

[13]. Lu R, Zhao X, Li J, Niu P, Yang B, Wu H, et al. Genomic characterisation and epidemiology of 2019 novel coronavirus: implications for virus origins and receptor binding. Lancet. 2020 Feb 22;395(10224):565-574.Pubmed PMID: 32007145.

[14]. Andersen KG, Rambaut A, Lipkin WI, Holmes EC, Garry RF. The proximal origin of SARS-CoV-2. Nat. Med. 2020 Apr;26(4):450-2.

[15]. Su S, Wong G, Shi W, Liu J, Lai AC, Zhou J, et al. Epidemiology, genetic recombination, and pathogenesis of coronaviruses. TRENDS MICROBIOL. 2016 Jun 1;24(6):490 - 502.

[16]. Hu D, Zhu C, Ai L, He T, Wang Y, Ye F, et al. Genomic characterization and infectivity of a novel SARS - like coronavirus in Chinese bats. Emerg. microbes \& infect. 2018 Dec 1;7(1):1-10.

[17]. Meledandri, G., Borgese, L., \& Marangi, M. (2017). I reservoirs delle malattie umane. In L. Borgese, M. Marangi, G. Meledandri (Eds.), Ebola e gli altri filoviridae (pp. 163-166). Alpes Italia.

[18]. Kohl C, Kurth A. European bats as carriers of viruses with zoonotic potential. Viruses. 2014 Aug 13;6(8):3110-28. Pubmed PMID: 25123684.

[19]. Xiao K, Zhai J, Feng Y, Zhou N, Zhang X, Zou JJ, et al. Isolation of SARSCoV-2-related coronavirus from Malayan pangolins. Nature. 2020 May 7: $1-4$.

[20]. Lam TT, Jia N, Zhang YW, Shum MH, Jiang JF, Zhu HC, et al. Identifying SARS-CoV-2-related coronaviruses in Malayan pangolins. Nature. 2020 Mar 26:1-4.

[21]. Ren W, Li W, Yu M, Hao P, Zhang Y, Zhou P, et al. Full - length genome sequences of two SARS-like coronaviruses in horseshoe bats and genetic variation analysis. J Gen Virol. 2006 Nov;87(11):3355-3359. Pubmed PMID: 17030870.

[22]. Gaubert P, Antunes A, Meng H, Miao L, Peigne S, Justy F, et al. The Complete Phylogeny of Pangolins: Scaling Up Resources for the Molecular Tracing of the Most Trafficked Mammals on Earth. J Hered. 2018 May 11;109(4):347-359. Pubmed PMID: 29140441.

[23]. Fortey R. Life: A Natural History of the First Four Billion Years of Life on Earth. Science. 1998 Jun 5;280(5369):1542-4.

[24]. Song HD, Tu CC, Zhang GW, Wang SY, Zheng K, Lei LC, et al. Cross-host evolution of severe acute respiratory syndrome coronavirus in palm civet and human. Proc Natl Acad Sci U S A. 2005 Feb 15;102(7):243-5. Pubmed PMID: 15695582.

[25]. Wu D, Wu T, Liu Q, Yang Z. The SARS-CoV-2 outbreak: what we know. Int J Infect Dis. 2020 Mar 12;94:44-48.

[26]. Liu K, Pan M, Xiao Z, Xu X. Neurological manifestations of the coronavirus (SARS-CoV-2) pandemic 2019-2020. J. Neurol. Neurosurg. Psychiatry. 2020 Jun 1;91(6):669-70.

[27]. ISS. ISS per COVID-19-ISS. Retrieved 25 June 2020 from https://www. iss.it/coronavirus

[28]. Notkins AL. Viral infections: Mechanisms of immunologic defense and injury. Hospital Practice. 1974 Sep 1;9(9):65-75.

[29]. Tse GM, To KF, Chan PK, Lo AW, Ng KC, Wu A, et al. Pulmonary pathological features in coronavirus associated severe acute respiratory syndrome (SARS). J. Clin. Pathol. 2004 Mar 1;57(3):260-5.

[30]. Guo YR, Cao QD, Hong ZS, Tan YY, Chen SD, Jin HJ, et al. The origin, transmission and clinical therapies on coronavirus disease 2019 (COV- 
ID-19) outbreak-an update on the status. Mil. Med. Res. 2020 Dec;7(1):10 .

[31]. Hall RC, Hall RC, Chapman MJ. The 1995 Kikwit Ebola outbreak: lessons hospitals and physicians can apply to future viral epidemics. Gen Hosp Psychiatry. 2008 Sep - Oct;30(5):446-52.Pubmed PMID: 18774428.

[32]. Van Bortel T, Basnayake A, Wurie F, Jambai M, Koroma AS, Muana AT, et al. Psychosocial effects of an Ebola outbreak at individual, community and international levels. Bull World Health Organ. 2016 Mar 1;94(3):210-4. Pubmed PMID: 26966332.

[33]. Sim K, Huak Chan Y, Chong PN, Chua HC, Wen Soon S. Psychosocial and coping responses within the community health care setting towards a national outbreak of an infectious disease. J Psychosom Res. 2010 Feb;68(2):195202.Pubmed PMID: 20105703.

[34]. Hansell N. The person-in-distress: On the biosocial dynamics of adaptation. NY: Behavioral Sciences Press. 1974.

[35]. Wolkon GH. Crisis theory, the application for treatment, and dependency. Compr. Psychiatry. 1972 Sep 1;13(5):459-64.

[36]. Ewing CP. Crisis intervention as psychotherapy. Oxford University Press; 1978.

[37]. Slaikeu KA. Crisis intervention: A handbook for practice and research. Allyn \& Bacon; 1984

[38]. Bloom BL, Asher SJ, White SW. Marital disruption as a stressor: a review and analysis. Psychol Bull. 1978 Jul;85(4):867-94.Pubmed PMID: 356075.

[39]. Dooley D, Catalano R. Economic change as a cause of behavioral disorder. Psychol. Bull. 1980 May;87(3):450-468.

[40]. Holmes TH, Rahe RH. The social readjustment rating scale. J Psychosom Res. 1967;11(2):213-218.

[41]. Rahe RH, Arthur RJ. Life change and illness studies: Past history and future directions. J HUM STRESS. 1978 Mar 1;4(1):3-15.

[42]. Hinrichsen, D., \& Pritchard, A.J. (2005). Mathematical systems theory I. Berlin: Springer.

[43]. Scott AC. The nonlinear universe: chaos, emergence, life. Springer Science \& Business Media. 2007 Oct 2

[44]. Cheng C, Cheung MW. Psychological responses to outbreak of severe acute respiratory syndrome: a prospective, multiple time-point study. J Pers. 2005
Feb;73(1):261-85.Pubmed PMID: 15660679.

[45]. Roth S, Cohen LJ. Approach, avoidance, and coping with stress. Am Psychol. 1986 Jul;41(7):813-819.

[46]. Yu HY, Ho SC, So KF, Lo YL. The psychological burden experienced by Hong Kong midlife women during the SARS epidemic. Stress and health. 2005 Aug;21(3):177-84

[47]. Peng EY, Lee MB, Tsai ST, Yang CC, Morisky DE, Tsai LT, et al. Population based post-crisis psychological distress: an example from the SARS oubreak in Taiwan. J Formos Med Assoc. 2010 Jul;109(7):524-32.Pubmed PMID: 20654792.

[48]. Main A, Zhou Q, Ma Y, Luecken LJ, Liu X. Relations of SARS-related stressors and coping to Chinese college students' psychological adjustment during the 2003 Beijing SARS epidemic. J Couns Psychol. 2011 Jul;58(3):410-23. Pubmed PMID: 21574694.

[49]. McCauley M, Minsky S, Viswanath $K$. The $H 1 N 1$ pandemic: media frames, stigmatization and coping. BMC Public Health. 2013 Dec 3;13:1116.Pubmed PMID: 24299568.

[50]. Taha SA, Matheson K, Anisman H. H1N1 was not all that scary: Uncertainty and stressor appraisals predict anxiety related to a coming viral threat. Stress and health. 2014 Apr;30(2):149-57.

[51]. Rabelo I, Lee V, Fallah MP, Massaquoi M, Evlampidou I, Crestani R, et al. Psychological Distress among Ebola Survivors Discharged from an Ebola Treatment Unit in Monrovia, Liberia - A Qualitative Study. Front Public Health. 2016 Jul 4;4:142. Pubmed PMID: 27458576.

[52]. Schwerdtle PM, De Clerck V, Plummer V. Experiences of Ebola Survivors Causes of Distress and Sources of Resilience. Prehosp Disaster Med. 2017 Jun;32(3):234-239. Pubmed PMID: 28215187.

[53]. Wang C, Pan R, Wan X, Tan Y, Xu L, Ho CS, et al. Immediate Psychological Responses and Associated Factors during the Initial Stage of the 2019 Coronavirus Disease (COVID-19) Epidemic among the General Population in China. Int J Environ Res Public Health. 2020 Mar 6;17(5):1729. Pubmed PMID: 32155789.

[54]. Del Vecchio, F. Metodi Statistici. Roma: Euroma La Goliardica.1988.

[55]. Last JM. A dictionary of epidemiology. Oxford university press; 2018. 